\title{
Electrochemical impedance spectroscopic evaluation of corrosion protection properties of polyurethane /polyvinyl chloride blend coatings on steel
}

\section{Abdulkareem Mohammed Ali Alsamuraee ${ }^{1}$, Harith Ibraheem Jaafer ${ }^{2}$, Hani Aziz Ameen ${ }^{3}$ and Ahmed Qasim Abdullah ${ }^{4}$}

\author{
${ }^{1}$ Baghdad Univ.,--Collage of Science, Chemistry Dept., Baghdad, Iraq. E- \\ mail:samuraee2000@hotmail.com \\ ${ }^{2}$ Baghdad Univ., Collage of Science, Physics Department, Baghdad, Iraq. \\ ${ }^{3}$ Dies and Tools Eng., Technical College, Baghdad, Iraq. E-mail : \\ haniazizameen@yahoo.com \\ ${ }^{4}$ Baghdad Univ., Collage of Science, Physics Department, Baghdad, Iraq. \\ ABSTRACT
}

\begin{abstract}
This paper aimed to evaluate the polyurethane $(\mathrm{pu})$ and polyurethane/polyvinyl chloride (90 $\mathrm{wt} . \% / 10 \mathrm{wt} . \%$ ) as organic coating of carbon steel substrate against marine environment (3.5 wt.\%) as a severe corrosion environment. The electrochemical impedance spectroscopy (EIS) and fitting impedance data by ZsimpWin 3.22 software were used to estimate the physical barrier of the samples for different exposure times. Different equivalent electrical circuits were taken for the physical barrier at different immersion times to get appropriate fitting. Both pu and pu/pvc coatings showed excellent corrosion protection for steel .The pu/pvc coating showed better protection and stability than pu coating against aggressive salt solution. The relation between dielectric properties (impedance spectrum) of coating film with their behavior as physical barrier protection gives useful information about electrochemical process and predicts the barrier protective behavior in natural environment.
\end{abstract}

\section{INTRODUCTION}

Corrosion of the metals is one of the most serious problems throughout the world (Bin Yao et al,2008). Several techniques have been used to protect metals from corrosion Among them, the polymer coatings may be the most widely used technique (Hosseini et al, 2007). Modern organic coatings are complex materials which must be observed and interpreted from the viewpoint of what has become known as Materials Science (Gordon ,2008). the protectiveness of organic coatings controlling corrosion processes by the barrier effect is dominated by the absence of any defect (pores, scratches, etc ) passing through the coating and reaching the substrate which can cause the initiation of corrosion (Schweitzer,2006 and Deflorian et al,2002).Where organic coating are effectively used for the protection of metals owing partly to their capacity to act as a physical barrier between the metal surface and the corrosive environment in which they perform their function (Gonza'lez-Garcl'et al,2007). Beginning in the 1970s, research electrochemists and materials scientists began to discover the power of Electrochemical Impedance Spectroscopy (EIS) as a tool for studying difficult and complicated systems (David Loveday et al ,2004). The physical barrier has been evaluated by electrochemical impedance spectroscopy (EIS)which had many advantages in comparison with the other electrochemical technique (Abdel Salam Hamdy et al,2006). During (EIS) experiments, a small amplitude AC signal is applied to the system being studied with different frequencies. By analysis of these responses in the frequency domain, different corrosion process may be deduced and studied .An equivalent electrical circuit for a corrosion system is often used in the analysis of EIS measurements (Zhen-Tian CHANG ,2007)

\section{Theory of EIS}

EIS data is commonly analyzed by fitting it to an equivalent electrical circuit model (Dipti Kataria, 2005). The Randle cell is a simple yet useful combination of a capacitor and two resistors figure 
(1) this electrical circuit can be used to represent a coating or corroding metal, although the values and meaning of the components are different (David
Loveday, 2004). Randle cell can't recover all the physical and chemical processes occur during the corrosion process (electrochemical process).

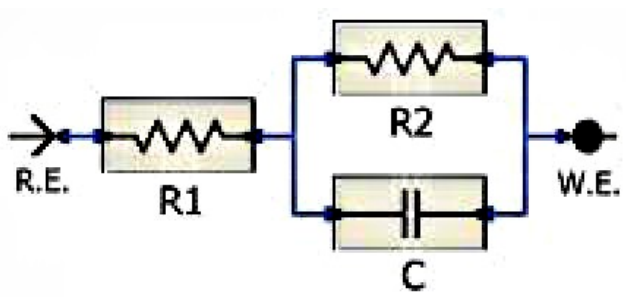

Figure(1): The Randles cell equivalent circuit.

Therefore we need to use more complicated equivalent circuit gives appropriate fitting with experimental. A change of elements values and/or the shape of equivalent circuit during test process will be indicated to what happened in sample under study and evaluation the organic coating . in ( Figure 2) the equivalent circuit is overlaid on schematic of a coated metal substrate ( David Loveday et al, 2004). EIS is one of the most frequently used methods for providing information on the performance of organic coating on a metals (Jiho Kang,2006).

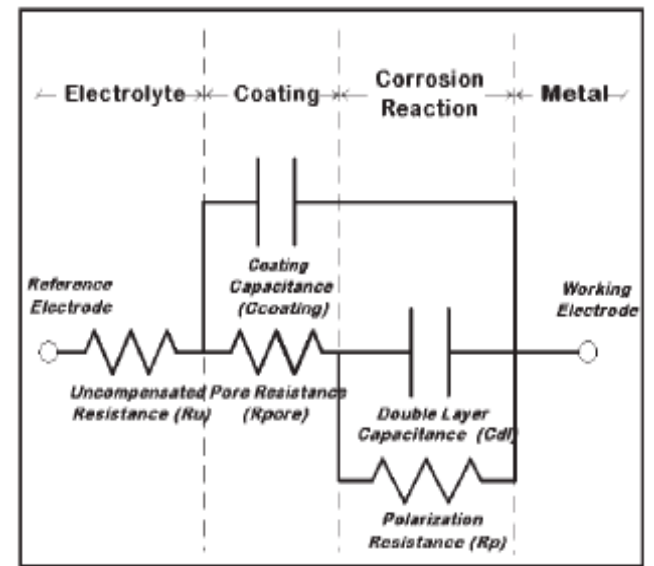

Figure;(2); Equivalent circuit of an organic coating on a metal substrate overlaid on a schematic of a painted metal surface.

A typical impedance spectrum for a corroding metal under change transfer control is shown in Figures(3\&4). Presentation of impedance data is often done by use of three different graphs the Nyquist shown in Figure(3),plots the real( $\left.Z^{\prime}\right)$ and imaginary component ( $Z$ ") of the impedance on $x$ and $y$ axis respectively . For Nyquist plot, shown corrosion data it can be assumed that the frequency decrease from left to right but the graph doesn't display the frequency for data collected, hence the same data is often also displayed using Bode plot show the relation between the frequency (f) with phase angle $(\theta)$ and the equivalent impedance $(z)$ as shown in Figure(4). (Jan Magnus ,2007) 


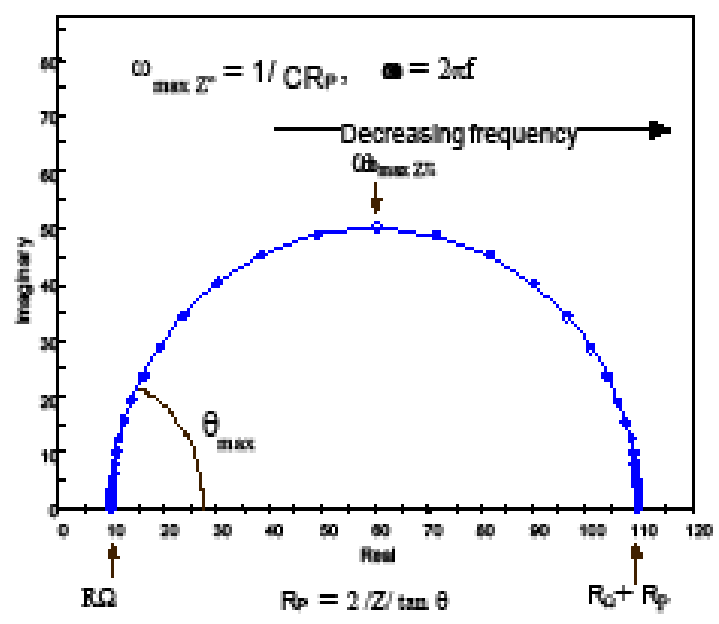

Fig 3;Nyquist plot for a simple electrochemical system.

The elements of equivalent circuit are as follows:

a. Solution Resistance (Rsol): Solution Resistance is the resistance of the electrolyte between the working electrode and reference electrode. For studies of organic coatings, the electrolyte is very conductive, so Rsol is usually very low and can be ignored.

b. Coating Capacitance (Cc): The capacitance of the organic coating is an important parameter to measure during coating failure. Because most coatings are relatively thick, the coating capacitance tends to be rather low-in the range of $1 \mathrm{nF} / \mathrm{cm}^{2}$. The physical and chemical properties of the coating that affect the capacitance are:

Ccoating $=(D)\left(k_{\circ}\right)(A) / t$

where $D$ is the dielectric constant of the coating, $k_{0}$ is $8.85 \times 10-14$ Farads/cm, $A$ is the area $\left(\mathrm{cm}^{2}\right)$, and $\mathrm{t}$ is the thickness (cm) (Jiho Kang ,2006).

Constant phase element (CPE)or(Q) instead of a capacitor was used to model the coating-metal interface in this study. A CPE has been described as an imperfect capacitor. The capacitor is related to the magnitude of the impedance (|Zcpe|) by equation 5:

Zcpe $=\left(1 / Y_{0}\right) /(j \cdot \omega)^{n}$

$Y_{0}$ is a constant, $j=(-1)^{1 / 2}, \omega=2 \pi f$, and $n$ is a constant between 0 and 1 . If $Z=1, Y_{0}$ is the capacitance. Use of a constant phase element generally gives a better fit with a model. When the system shows behavior that has been attributed to surface heterogeneity or to continuously distributed

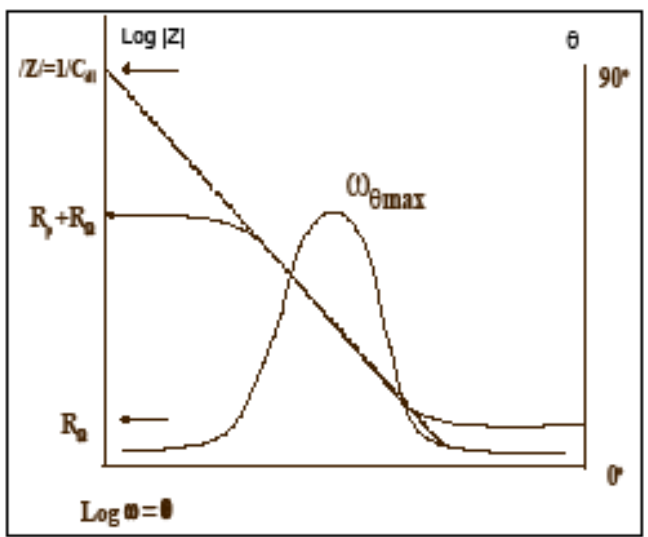

Fig 4;Bode plot for a simple electrochemical system. time constants for charge-transfer reactions (Vicky Mei-Wen Huang et al, 2007) .

c. Warburg Diffusion(W): Diffusion can create impedance known as the Warburg impedance. This impedance depends on the frequency of the potential perturbation. At high frequencies the Warburg impedance is small since diffusing reactants don't have to move very far. At low frequencies the reactants have to diffuse farther, thereby increasing the Warburg impedance. On a Nyquist plot the infinite Warburg impedance appears as a diagonal line with a slope of 0.5 . On a Bode plot, the Warburg impedance exhibits a phase shift of $45^{\circ}$. The same data is plotted in the Bode format. The phase angle of Warburg impedance is $45^{\circ}$ (Ali Hassanzadeh et al, 2004). This circuit models a cell where polarization is due to a combination of kinetic and diffusion processes. The lower frequency limit was moved down to $1 \mathrm{mHz}$ to better illustrate the differences in the slope of the magnitude and in the phase between the capacitor and the Warburg impedance.( Dipti Kataria ,2005).

d. Polarization Resistance $\left(\mathbf{R}_{\mathrm{p}}\right)$ : The corrosion rate of the metal substrate beneath the coating is described by the polarization resistance. For a metal in the absence of a coating, the corrosion rate can be determined from the polarization resistance. The polarization resistance is inversely proportional to the corrosion rate.

e. Double Layer Capacitance (Cdl): The coating is not the only structural feature of the sample that gives rise to a capacitance. There is a charge on the 
metal electrode and a charge in the electrolyte that are separated by the metal electrolyte interface. Since this interface is commonly known as the double layer in electrochemical theory, the capacitance is called the double layer capacitance and abbreviated $\mathrm{Cdl}$. The value of Cdl is usually in the range of 10-40 $\mu \mathrm{F} / \mathrm{cm}^{2}$. This capacitance is much higher than Ccoating $\left(10-9 \mathrm{~F} / \mathrm{cm}^{2}\right)$. The two circuit elements that initially dominate the impedance are the coating capacitance and the pore resistance (Dipti Kataria ,2005 and Jiho Kang ,2006).

Experimental: The sample prepared as outlined below;

1. Specimen of $1 \mathrm{~cm}$ length of each plated bar was cut using diamond cutting wheel.

2. Some specimens were mounted by hot molding machine using a suitable mould

3. Using grinding wheel machine type metallographic Lapping/ Polishing machine (UN 1 POL-820) all samples were grinded using different grinding paper grades $(120,240,320.600,800$, and 1200).

4. Samples were polished using polishing wheel with proper cloth and diamond emulsion $(6 \mu \mathrm{m})$, obtaining surface free from scratches.

5. The sample cleaned thoroughly with solvent, then rinsed in distilled water to remove any traces of the cleanser.

6. Coating the samples with polyurethane and polyurethane/pvc blend by using dip method.

7. Examination of coating thickness using ultrasonic coat thickness gauge (Non Destructive coating thickness gauges Type T-8822 produced by Times Group Company) and optical microscope supplied with video camera type NickonECLIPSE-ME600 for all types of application to measure coating on steel and steel substrates.

The electrochemical cell was prepared by placing the samples (commonly called working electrode) in a cell. The exposed samples surface area of 1.76625 $\mathrm{cm}^{2}$ exposure to environment (electrolyte). A saturated calomel electrode (SCE) was employed as reference electrode, and a platinum counter electrode positioned parallel to the exposed sample completed the cell. The cell was filled with a $0.5 \mathrm{M}$ $\mathrm{NaCl}$ aqueous solution $(3.5 \mathrm{wt} . \% \mathrm{NaCl}$ ) and remained open to the air. The measurements were carried at ambient temperature $\left(30^{\circ} \mathrm{C}\right)$. EIS measurements were carried out at the Ecorr potential of the samples in the frequency range $0.01-10,000 \mathrm{~Hz}$. The rms width of the sinusoidal voltage signal applied to the system was $10 \mathrm{mV}$. EIS data were plotted in terms of both Nyquist (imaginary component of the impedance as a function of the real component) and Bode ( the impedance modulus $|Z|$ and phase angle / as a function of the logarithm of the frequency f) diagrams. The procedures was employed for the analysis of the experimental impedance spectra. By fitting the spectra to model equivalent circuits by using the ZsimpWin 3.22 software (Yeum ,2007), and the circuit components were subsequently correlated to the physicochemical processes occurring in the system.

\section{RESULTS AND DISCUSSION}

When we compared between experimental impedance spectrum Bode lots for two samples (pu \& $\mathrm{pu} / \mathrm{pvc})$ in Figures(5\&7) with the fitted curves in Figures(6\&8) respectively we observed that good similarity between them ,this indicated that there are a good fitting and appropriate equivalent circuit to represent the electrochemical process.

The equivalent circuit of pu and pu/pvc coating are appears in table(1) these circuits compared to the circuit in Figure (2). It had been observed that the capacitor replaced by a constant phase element (CPE) for all exposure times and also it showed another element which was the Warburg diffusion (W).

Exist (CPE) in the circuit is meaning that the coating is imperfect or not pure capacitance behavior because the test provides a severe corrosion environment $(3.5 \mathrm{wt} . \% \mathrm{NaCl})$ that is generally believed to simulate the long time. If there is a case like this it is necessary to take the (CPE) as one of equivalent circuit elements then discuss the (CPE)'s constants (Yo) \& (n) how do they change with exposure time by using equation $\left\{\mathbf{C}=\left(\mathrm{Yo}^{*} \mathbf{R}\right)^{(1 / n)}\right.$ I $\mathbf{R}\}$ to calculate the equivalent capacitance of the (CPE).

The Warburg impedance in equivalent circuit of a certain immersion time, which gave an indication that the polarization was occurring due to both kinetic and diffusion mechanism. Obtaining (CPE) and (W) in circuits, provides credibility to the appropriate circuit since it's hard to find organic coating as a perfect capacitor but there are electrochemical and diffusion processes caused deterioration of coating film. The required circuit element values for fitting the impedance plots are given in tables(2\&3), the values 
of coating in the range of excellent protection for two coating types. By observing the $\left(\mathrm{Y}_{\mathrm{o} 1}\right)$ values in tables(2\&3) they appear that the pu/pvc coating blend is better than pu. As would be expected, changes in $R_{s}$ are negligible since the Ohmic resistance of the electrolyte remains essentially unchanged.

Figures (9\&10) show the relation between the frequency and phase angle which represents the general behavior of an equivalent circuit as a capacitor. When the phase angle close to $90^{\circ}$ the sample tends to be pure or perfect capacitor that means good physical barrier properties, on the other hand if the phase angle close to 0 the sample tends to be resistor and far from pure capacitor. From this the pu/pvc coating better than pu coating as shown in Figures (9\&10).

Figures (11\&12) show the relation between the frequency and general equivalent

impedance of the circuit for all exposure times. The decreasing of the impedance with the exposure time at low frequency in Figure(11) for pu coating indicates that the protection film was deteriorating by a severe corrosion environment. In Figure(12) observed that the impedance have slight change this means that the pu/pvc have good stability in corrosion environment.

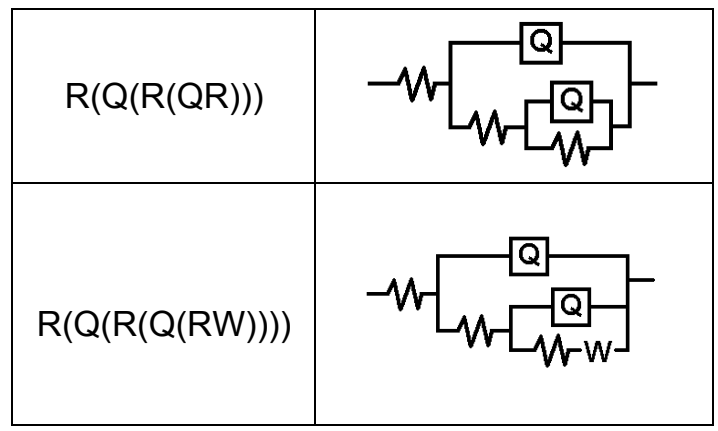

Table (1); configuration of equivalent circuits and their symbols.

\begin{tabular}{|c|c|c|c|c|c|c|c|c|c|}
\hline $\begin{array}{c}\text { Exposure } \\
\text { time(hour) }\end{array}$ & $\mathbf{E . C .}$ & $\begin{array}{c}\mathbf{R}_{\mathbf{u}}=\mathbf{R}_{\mathbf{s}} \\
(\boldsymbol{\Omega})\end{array}$ & $\begin{array}{c}\mathbf{Y}_{\mathbf{o} 1} \\
\left(\mathbf{S . s e c}^{\wedge} \mathbf{n}\right)\end{array}$ & $\mathbf{n}_{\mathbf{1}}$ & $\begin{array}{c}\mathbf{R}_{\text {pore }} \\
(\boldsymbol{\Omega})\end{array}$ & $\begin{array}{c}\mathbf{Y}_{\mathbf{o} 2} \\
(\mathbf{S . s e c} \mathbf{n})\end{array}$ & $\mathbf{n}_{\mathbf{2}}$ & $\mathbf{R}_{\mathbf{p}}(\boldsymbol{\Omega})$ & $\begin{array}{c}\mathbf{W} \\
\left(\mathbf{S} . \mathbf{s e c}^{\wedge} \mathbf{0 . 5}\right)\end{array}$ \\
\hline 0.5 & $\mathrm{R}(\mathrm{Q}(\mathrm{R}(\mathrm{QR})))$ & 0.01 & $4.15 \mathrm{E}-9$ & 1 & 684.2 & $2.6 \mathrm{E}-5$ & 0.425 & $4.76 \mathrm{E} 4$ & ----- \\
\hline 1 & $\mathrm{R}(\mathrm{Q}(\mathrm{R}(\mathrm{QR})))$ & 0.01 & $2.73 \mathrm{E}-8$ & 0.867 & 904.7 & $3.9 \mathrm{E}-5$ & 0.449 & $5.16 \mathrm{E} 4$ & --- \\
\hline 14 & $\mathrm{R}(\mathrm{Q}(\mathrm{R}(\mathrm{Q}(\mathrm{RW}))))$ & 0.01 & $3.33 \mathrm{E}-6$ & 0.520 & 1080 & $8.0 \mathrm{E}-5$ & 0.4748 & $1.93 \mathrm{E} 4$ & 3131 \\
\hline 22 & $\mathrm{R}(\mathrm{Q}(\mathrm{R}(\mathrm{QR})))$ & $\begin{array}{c}2.5 \mathrm{E}- \\
5\end{array}$ & $1.54 \mathrm{E}-6$ & 0.571 & 998.4 & $7.162 \mathrm{E}-5$ & 0.3807 & $4.58 \mathrm{E} 4$ & --- \\
\hline 38 & $\mathrm{R}(\mathrm{Q}(\mathrm{R}(\mathrm{QR})))$ & 0.01 & $3.42 \mathrm{E}-6$ & 0.520 & 1086 & $1.12 \mathrm{E}-4$ & 0.606 & $1.25 \mathrm{E} 4$ & --- \\
\hline
\end{tabular}


Table (2); electrochemical parameters of equivalent circuits obtained from best fit to impedance data for polyurethane coating.

\begin{tabular}{|c|c|c|c|c|c|c|c|c|c|}
\hline $\begin{array}{c}\text { Exposure } \\
\text { time(hou } \\
\text { r) }\end{array}$ & E.C. & $\begin{array}{c}\mathbf{R}_{\mathrm{u}}=\mathbf{R}_{\mathrm{s}} \\
(\Omega)\end{array}$ & $\begin{array}{c}Y_{\mathrm{o} 1} \\
\left(\mathrm{~S} . \mathrm{sec}^{\wedge}\right. \\
\mathrm{n})\end{array}$ & $\mathrm{n}_{1}$ & $\begin{array}{l}R_{\text {pore }} \\
(\Omega)\end{array}$ & $\begin{array}{c}Y_{02} \\
\left(S . \sec ^{\wedge}\right. \\
n)\end{array}$ & $\mathrm{n}_{2}$ & $\stackrel{R_{p}(\Omega}{)}$ & $\begin{array}{c}W \\
\left(S . \sec ^{\wedge} 0 .\right. \\
5)\end{array}$ \\
\hline-1 & $\begin{array}{c}\mathrm{R}(\mathrm{Q}(\mathrm{R}(\mathrm{QR}) \\
))\end{array}$ & 0.2529 & $\begin{array}{c}6.55 \mathrm{E}- \\
11\end{array}$ & 1 & 4215 & 3.86E-4 & $\begin{array}{c}0.2 \\
8\end{array}$ & 4587 & ----- \\
\hline 4 & $\begin{array}{c}\mathrm{R}(\mathrm{Q}(\mathrm{R}(\mathrm{Q}(\mathrm{R} \\
\mathrm{W}))))\end{array}$ & 0.1874 & $\begin{array}{c}1.653 \mathrm{E}- \\
10\end{array}$ & $\begin{array}{c}0.92 \\
73 \\
\end{array}$ & 5247 & $3.20 \mathrm{E}-4$ & 0.8 & 7921 & $5.8 \mathrm{E} 12$ \\
\hline 14 & $\begin{array}{c}\mathrm{R}(\mathrm{Q}(\mathrm{R}(\mathrm{QR}) \\
))\end{array}$ & 0.01 & $\begin{array}{c}1.139 \mathrm{E}- \\
10\end{array}$ & $\begin{array}{c}0.95 \\
22\end{array}$ & 4773 & $3.5 \mathrm{E}-4$ & 0.8 & $\begin{array}{c}1.7 \mathrm{E} \\
15\end{array}$ & ----- \\
\hline 24 & $\begin{array}{c}\mathrm{R}(\mathrm{Q}(\mathrm{R}(\mathrm{QR}) \\
))\end{array}$ & ---- & $1.8 \mathrm{E}-4$ & $\begin{array}{c}0.29 \\
19\end{array}$ & 5584 & $1.27 \mathrm{E}-3$ & 1 & 6709 & ---- \\
\hline
\end{tabular}

Table(3); electrochemical parameters of equivalent circuits obtained from best fit to impedance data for polyurethane/pvc blend coating.

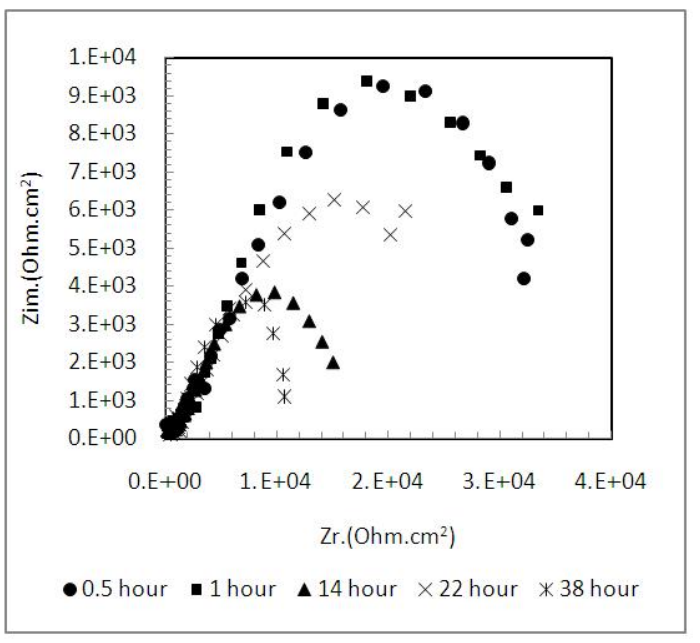

Figure(5);Nyquist plots of experimental data for pu coating with different exposure time.

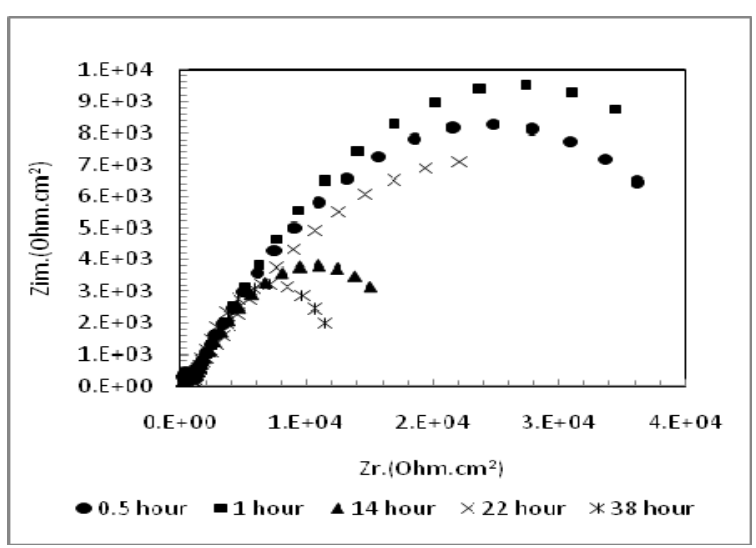

Figure(7);Nyquist plots of experimental data for pu/pvc coating with different exposure time.

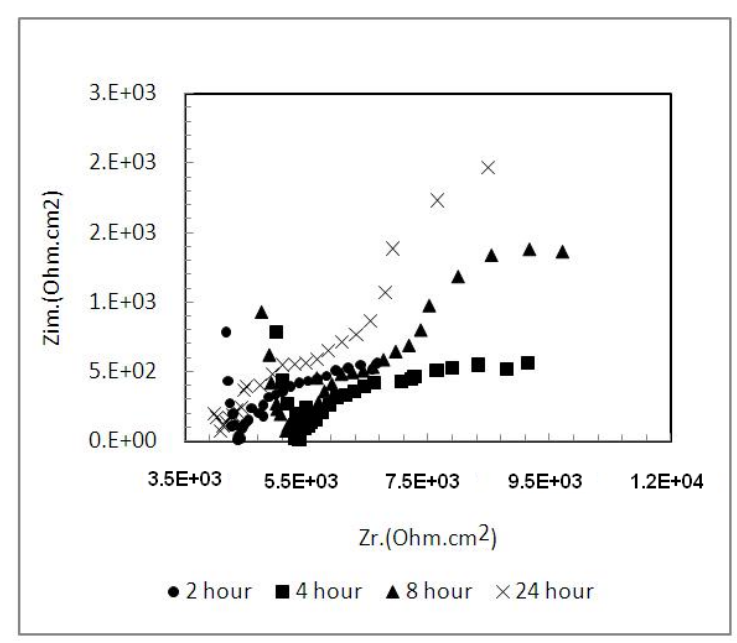

Figure(6);Nyquist plots of fitting data for pu coating with different exposure time.

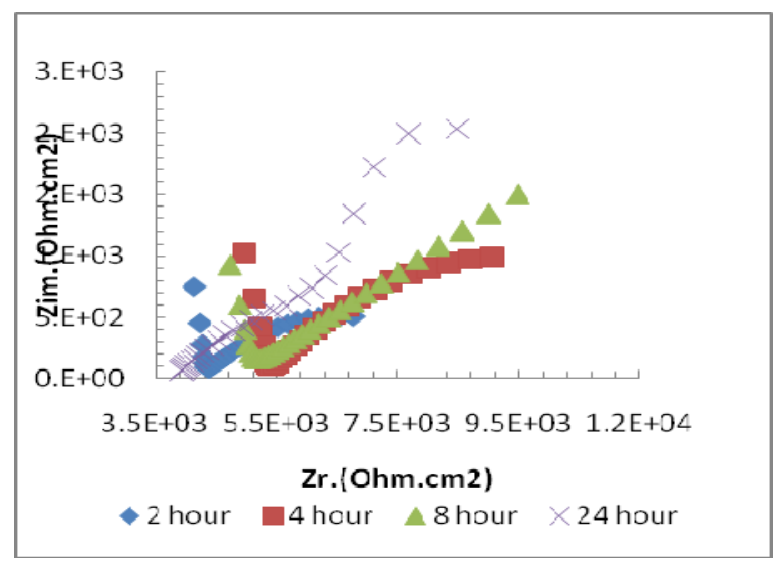

Figure(8);Nyquist plots of fitting data for pu/pvc coating with different exposure time. 
Am. J. Sci. Ind. Res., 2011, 2(5): 761-768
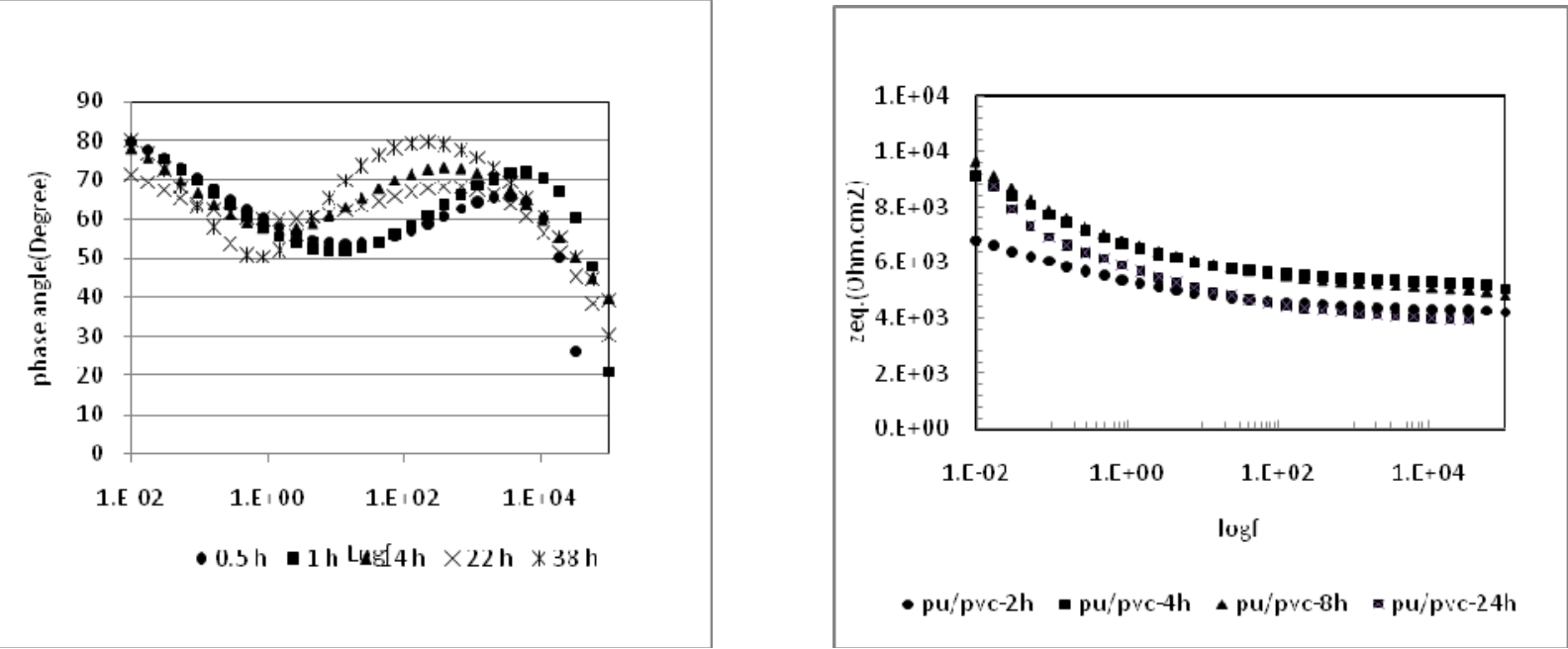

Figure(9) Bode plot between frequency versus phase angle for pu.

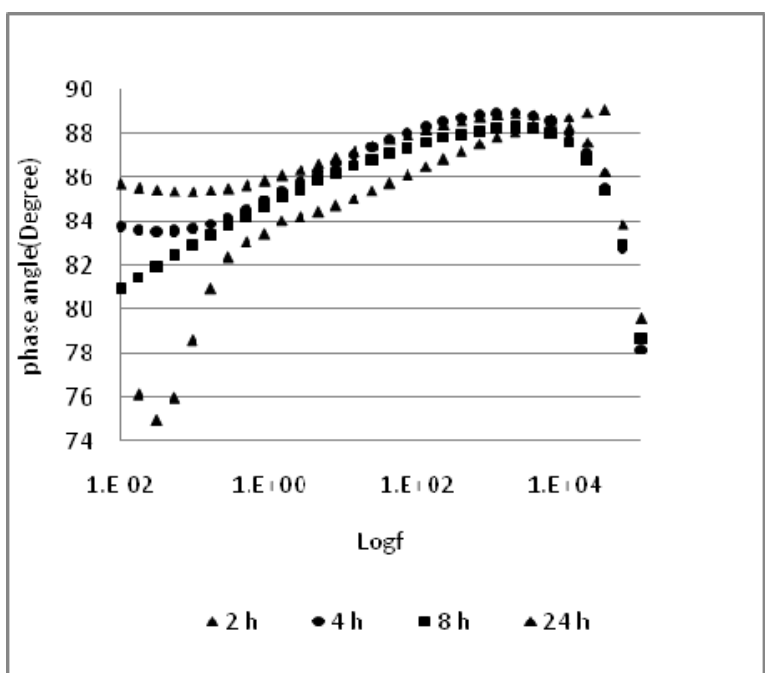

Figure(10); Bode plot between frequency versus phase angle for pu.

\section{CONCLUSION}

A purely capacitive behavior is characteristic of an effective barrier film .it was initially observed for two system coating protection at different immersion times .pu/pvc coating continues closed to pure capacitor for most of the frequency range covered in the measurements. The two systems coatings applied on carbon steel provide very effective protection against corrosion. Pu/pvc coating appeared good stability in corrosion environment.

\section{REFERENCES}

1- Bin Yao, Gengchao Wang , Jiankun Ye, and Xingwei Li, Materials Letters,vol.62,pp: 1775-1778,(2008).

2-M.G. Hosseini, M. Sabouri ,and T. Shahrabi, Progress in Organic Coatings,vol.60,pp:178-185 (2007).

Figure(11);Bode plots of polurethane coating with different exposure time in, $3.5 \%$ wt. $\mathrm{NaCl}$ solution.

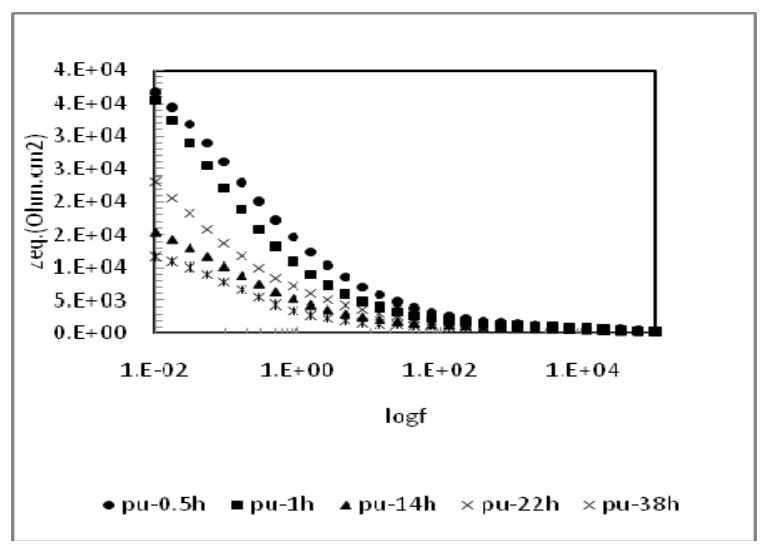

Figure( 12);Bode plots of pu/pvc coating with different exposure time in, $3.5 \%$ wt. $\mathrm{NaCl}$ solution.

3-Gordon B. , J. Coat. Technol. Res., vol.5 (2)pp: 133155,(2008).

4- Schweitzer, Philip A.,"paint and coatings applications and Corrosion Resistance",1thedition, Taylor \& Francis Group (2006).

5- F. Deflorian, L. Fedrizzi, S. Rossi and P.L. Bonora, Journal of Applied Electrochemistry,vol. 32,pp: 921927,( 2002).

6- Y. Gonza'lez-Garci', S. Gonza'lez, R.M. Souto, Corrosion Science,vol. 49 ,pp:3514-3526, (2007).

7-David Loveday, Pete Peterson, and Bob Rodgers"Evaluation of Organic Coatings with Electrochemical Impedance Spectroscopypart1",coating tech., August (2004). 
8- Abdel Salam Hamdy, E. El-Shenawy and T. El-Bitar Int. J. Electrochem. Sci.,vol.pp:1171-180, (2006).

9- Zhen-Tian CHANG, Ph.D.Thesis," Corrosion Rate of Steel Reinforcement in Concrete in Seawater and Influence of Concrete Crack Width", The University of New South Wales, March (2007).

10- Dipti Kataria,Ms.C. Thesis," Polyaniline Clay Polyimide Hybrid Nanocomposite Coatings for Corrosion Protection of AA 2024", University of Cincinnati,( 2005).

11- David Loveday, Pete Peterson, and Bob Rodgers"Evaluation of Organic Coatings with

Electrochemical Impedance Spectroscopy-part2",coating tech., October (2004).

12- Jiho Kang ,Ph.D. Thesis," Electrochemical Studies of Coatings and Thin Films", Ohio State University,(2006).
13-Jan Magnus G.,Ph.D. Thesis,"corrosion protection using conducting polymers",university of Wollongong,(2007).

14- Vicky Mei-Wen Huang, Vincent Vivier,Mark E. Orazem, Nadine Pébère, and Bernard Tribollet, Journal of The Electrochemical Society, vol.154 (2),pp: C81-C88, (2007).

15- Ali Hassanzadeh, Mohammad Hossein Habibi, and Asghar Zeini-Isfahani, Acta Chim. Slov., vol.51, pp:507-527,(2004)

16-B. Yeum,Ph.D.Thesis, "Electrochemical impedance spectroscopy: data analysis software". Echem Software, Ann Arbor,Michigan ( 2007). 